\title{
Fatigue damage healing model based on dislocation reverse-back under unconstraint vibration condition for copper film
}

\author{
Haimeng Zhang ${ }^{1}$, De-Guang Shang ${ }^{2}$, Xiao-Dong Liu ${ }^{1}$, and Yu Zhang ${ }^{1}$ \\ ${ }^{1}$ Affiliation not available \\ ${ }^{2}$ Beijing University of Technology
}

February 14, 2021

\begin{abstract}
In this investigation, it is found that the generated elastic stress during the unconstraint vibration treatment process can act as the dislocation driving stress on the dislocation in the micro-scale. When the sum of the dislocation driving stress, the image stress and the back stress exceeds the motion resistance of the dislocations in a pile-up, the dislocations begin to reverse back, and the pile-up disappear. Based on this principle, a fatigue damage-healing model under unconstraint vibration condition was proposed. The verified results showed that the damaged copper film can be effectively healed by the vibration guided by the model calculation.
\end{abstract}

\section{Hosted file}

Manuscript .pdf available at https://authorea.com/users/395736/articles/508882-fatigue-damagehealing-model-based-on-dislocation-reverse-back-under-unconstraint-vibration-conditionfor-copper-film

\section{Hosted file}

Tables.pdf available at https://authorea.com/users/395736/articles/508882-fatigue-damagehealing-model-based-on-dislocation-reverse-back-under-unconstraint-vibration-conditionfor-copper-film

\section{Hosted file}

Figures.pdf available at https://authorea.com/users/395736/articles/508882-fatigue-damagehealing-model-based-on-dislocation-reverse-back-under-unconstraint-vibration-conditionfor-copper-film 